Contract No. and Disclaimer:

This manuscript has been authored by Savannah River Nuclear Solutions, LLC under Contract No. DE-AC09-08SR22470 with the U.S. Department of Energy. The United States Government retains and the publisher, by accepting this article for publication, acknowledges that the United States Government retains a non-exclusive, paid-up, irrevocable, worldwide license to publish or reproduce the published form of this work, or allow others to do so, for United States Government purposes. 


\title{
Distribution of lanthanide and actinide elements between bis-(2-ethylhexyl)phosphoric acid and buffered lactate solutions containing selected complexants
}

\author{
Tracy S. Rudisill, David P. DiPrete, and Major C. Thompson \\ Savannah River National Laboratory \\ Aiken, SC 29808
}

\begin{abstract}
With the renewed interest in the closure of the nuclear fuel cycle, the TALSPEAK process is being considered for the separation of Am and $\mathrm{Cm}$ from the lanthanide fission products in a next generation reprocessing plant. However, an efficient separation requires tight control of the $\mathrm{pH}$ which likely will be difficult to achieve on a large scale. To address this issue, we measured the distribution of lanthanide and actinide elements between aqueous and organic phases in the presence of complexants which were potentially less sensitive to $\mathrm{pH}$ control than the diethylenetriaminepentaacetic (DTPA) used in the process. To perform the extractions, a rapid and accurate method was developed for measuring distribution coefficients based on the preparation of lanthanide tracers in the Savannah River National Laboratory neutron activation analysis facility. The complexants tested included aceto-, benzo-, and salicylhydroxamic acids, $\mathrm{N}, \mathrm{N}, \mathrm{N}^{\prime}, \mathrm{N}^{\prime}$-tetrakis(2-pyridylmethyl)ethylenediamine (TPEN), and ammonium thiocyanate $\left(\mathrm{NH}_{4} \mathrm{SCN}\right)$. The hydroxamic acids were the least effective of the complexants tested. The separation factors for TPEN and $\mathrm{NH}_{4} \mathrm{SCN}$ were higher, especially for the heaviest lanthanides in the series; however, no conditions were identified which resulted in separations factors which consistently approached those measured for the use of DTPA.
\end{abstract}

\section{Keywords}

TALSPEAK process, americium/curium separation, lanthanide elements, HDEHP

\section{Introduction}

Nuclear energy has played a major role in supplying power to US customers for decades and will continue as a key technology utilized to meet energy demands. The US Department of Energy's Office of Nuclear Energy (DOE-NE) is responsible for the research and development (R\&D) activities to ensure that nuclear power remains a viable option for energy production. One specific objective of DOE-NE's R\&D roadmap is the development of sustainable nuclear fuel cycles including the development of advanced separation technologies to recover the actinides from used nuclear fuels [1]. When fuel is removed from a nuclear reactor, approximately $95 \%$ of the initial $U$ is still present in the fuel. The fuel also contains higher actinides (e.g., $\mathrm{Np}, \mathrm{Pu}, \mathrm{Am}$, and $\mathrm{Cm}$ ) which can also be recovered, fabricated into fuels or targets, and used to generate additional energy. Table 1 summarizes the composition of a typical pressurized water reactor fuel after removal from the reactor and 10 years of cooling. Used reactor fuels are currently reprocessed in several countries using the PUREX process [3] to recover the $\mathrm{U}$ for re-enrichment and $\mathrm{Pu}$ for use in mixed oxide fuels. However, the small amounts of $\mathrm{Np}$, Am, and $\mathrm{Cm}$ (minor actinides) produced during fuel irradiation are not recovered and are currently discarded with the fission products as high level waste. If desired, Np produced in used reactor fuels can be recovered by making slight modifications to the PUREX process to control the $\mathrm{Np}$ valence and extraction into the solvent [4,5] as was performed at the US DOE's Savannah River Site for the production of ${ }^{238} \mathrm{Pu}$ for heat source applications [6].

For complete closure of the nuclear fuel cycle, the Am and $\mathrm{Cm}$ isotopes produced during fuel irradiation must also be recovered. The isolation and purification of these materials would allow additional energy production following fabrication of fuels or targets for advanced reactors and improve the performance of a geological repository. However, an efficient separation process for $\mathrm{Am}$ and $\mathrm{Cm}$ has not been demonstrated on an industrial scale. One of the issues with the recovery of Am and $\mathrm{Cm}$ in a single process is the similarity of the chemistry of the lanthanide fission products. Solvent extraction processes have been developed which allow the separation of Am, Cm, and the lanthanide elements from other waste components using extractants such as malonamids (in the DIAMEX process) or phosphine oxides (in the TRUEX or TPO processes) [7]. The subsequent separation of the Am and Cm from the lanthanide fission products requires a separate process. In 1964, Weaver and Kappelmann [8] reported the development of the TALSPEAK process to separate transplutonium elements from the lanthanides by preferentially extracting the lanthanides from an aqueous solution containing lactic acid and the sodium salt of diethylenetriaminepentaacetic (DTPA) into bis-(2-ethylhexyl)phosphoric acid (HDEHP). Under optimal conditions, 
$\mathrm{Nd}$ was the least extractable of the lanthanides and Cf was the most extractable of the transplutonium elements [9]. Weaver and Kappelmann also investigated the use of other aminopolycarboxylic acid as replacements for DTPA. The effectiveness of DTPA was found superior in separating Am from Ce and Eu when compared to nitriloacetic acid, hydroxyethylethylenediaminetriacetic acid, ethylenediaminetetraacetic acid, and

1,2-diaminocyclohexanetetraacetic acid. The TALSPEAK process can also be performed in a reverse mode in which the transplutonium elements and the lanthanide fission products are extracted into the HDEHP solvent and the transplutonium elements are stripped using a solution containing lactic acid and DTPA [10].

With the renewed interest in the closure of the nuclear fuel cycle, the TALSPEAK process is being considered for the separation of $\mathrm{Am}$ and $\mathrm{Cm}$ from the lanthanide fission products in a next generation reprocessing plant.

However, at this time, the level of understanding associated with the chemistry and the control of the process variables is not sufficient to deploy the technology on an industrial scale. One issue associated with the process is the control of the aqueous phase acidity. An efficient separation requires tight control of the $\mathrm{pH}(3-4)$ which would likely be difficult to consistently achieve on a large scale. To address this issue, we measured the distribution of lanthanide and actinide elements between aqueous and organic phases in the presence of alternate complexants to identify potential replacements for DTPA which may be less sensitive to $\mathrm{pH}$ control and thus improve the feasibility of deploying a modified process on an industrial scale.

Five complexants with the potential to replace DTPA in the TALSPEAK process were identified. The most effective separations are achieved in systems where the lanthanide elements interact more strongly with HDEHP and are complexed less strongly by the aqueous ligand than the actinide elements. Stability constants for aceto- and benzohydroxamic acid (AHA and BHA) have been measured for both lanthanide [11] and actinide [12] elements. The stability of the actinide complexes was much greater than the lanthanide complexes. For this reason, AHA, BHA, and salicylhydroxamic acid (SHA) were selected for testing. The other complexants selected for testing included $\mathrm{N}, \mathrm{N}, \mathrm{N}^{\prime}, \mathrm{N}^{\prime}$-tetrakis(2-pyridylmethyl)ethylenediamine (TPEN) and ammonium thiocyanate $\left(\mathrm{NH}_{4} \mathrm{SCN}\right)$. TPEN complexes of Am and Sm have modest stability constants, but do show selectivity for the actinide over the lanthanide element [13]. Ammonium thiocyanate has been used as a complexing agent in transuranic actinide/lanthanide separation processes in analytical chemistry $[14,15]$.

\section{Experimental}

\section{Tracer Preparation}

The lanthanide tracers used to measure distribution coefficients for the TALSPEAK process were prepared by neutron activation with the exception of ${ }^{154} \mathrm{Eu}$, which was purchased as a standard from Eckert \& Ziegler Isotope Products. The remaining lanthanide tracers were prepared using the Savannah River National Laboratory (SRNL)

${ }^{252} \mathrm{Cf}$ neutron-activation-analysis (NAA) facility [16]. During this study, the facility contained approximately $21 \mathrm{mg}$ of ${ }^{252} \mathrm{Cf}$ providing a thermal neutron flux of about $5 \times 10^{7} \mathrm{n} / \mathrm{cm}^{2} \cdot \mathrm{s}$ at the highest flux irradiation positions. To prepare the lanthanide tracers, a $\mathrm{HNO}_{3}$ solution containing naturally occurring lanthanides was initially prepared for activation in the SRNL NAA facility. The solution included La through Ho in the lanthanide series. The heaviest elements $(\mathrm{Er}, \mathrm{Tm}, \mathrm{Yb}$, and $\mathrm{Lu}$ ) were excluded due to low fission yields which results in the production of only small quantities of these elements in used nuclear fuel. In addition, activation of the heaviest lanthanide elements produces a number of isotopes which interfere with the quantification of isotopes of higher interest during a gamma pulse height analysis (GPHA) using a high purity germanium detector. The lanthanide solution was prepared by dissolving either the nitrate salt or oxide in $2 \mathrm{M} \mathrm{HNO}_{3}$ with subsequent dilution to approximately $1.3 \mathrm{M} \mathrm{HNO}_{3}$. The concentration of each element in the solution was based on preliminary calculations to produce lanthanide tracer in the University of Missouri Research Reactor and a test irradiation using the SRNL NAA facility. During the test irradiation, we established that tracers with sufficient activity to perform the extraction experiments could be produced in the SRNL facility following some adjustments to the mass of individual elements. The mass of each element used to produce $100 \mathrm{~mL}$ of solution and the activation products are summarized in Table 2. To produce lanthanide tracers, a $6 \mathrm{~mL}$ aliquot of the lanthanide solution was irradiated in the NAA facility for nominally $5 \mathrm{~d}$. A GPHA of the solution showed all of the desired isotopes with the exception of ${ }^{153} \mathrm{Gd}$ which was obscured by ${ }^{153} \mathrm{Sm}$ in the gamma spectrum. The activities of the daughter products ranged from approximately 0.2 to $20 \mathrm{kBq} / \mathrm{mL}$ $\left(1.2 \times 10^{4}\right.$ to $\left.1.2 \times 10^{6} \mathrm{dpm} / \mathrm{mL}\right)$. 
$\mathrm{The} \mathrm{Eu}, \mathrm{Np}, \mathrm{Pu}$, and $\mathrm{Am}$ tracers were prepared separately from the lanthanide tracers. To eliminate interferences in the gamma spectrum due to ${ }^{233} \mathrm{~Pa}$ (from ${ }^{237} \mathrm{~Np}$ decay), a ${ }^{239} \mathrm{~Np}$ tracer was prepared instead. The ${ }^{239} \mathrm{~Np}$ was recovered as the daughter from ${ }^{243} \mathrm{Am}$ which was purchased as a standard from Eckert \& Ziegler Nuclitec $\mathrm{GmbH}$. The ${ }^{239} \mathrm{~Np}$ activity was separated from the ${ }^{243} \mathrm{Am}$ using a TEVA ${ }^{\circledR}$ cartridge purchased from Eichrom Technologies LLC based on methods developed by Horwitz et al. [17]. ${ }^{238} \mathrm{Pu}$ and ${ }^{241} \mathrm{Am}$ were prepared from existing SRNL inventories of nuclear materials. The ${ }^{238} \mathrm{Pu}$ was purified by standard methods using Reillex ${ }^{\mathrm{TM}} \mathrm{HPQ}$ anion exchange resin purchased from Vertellus Specialties Inc. [18]. The ${ }^{241} \mathrm{Am}$ was purified using Eichrom's DGA resin based on N,N,N',N'-tetran-octyldiglycolamide as the extractant using methods developed by Horwitz et al. [19]. There was no need to control the valence of $\mathrm{Np}$ or Pu during the experiments; however, the predominant valences were likely $\mathrm{Np}$ (IV) based on the preparation of the ${ }^{239} \mathrm{~Np}$ tracer and $\mathrm{Pu}(\mathrm{IV})$ based on its stability in $\mathrm{HNO}_{3}$ solutions. Aliquots of the $\mathrm{Eu}$, $\mathrm{Np}, \mathrm{Pu}$, and $\mathrm{Am}$ tracer solutions sized to provide the desired activity were subsequently combined, evaporated to dryness and redissolved in a $0.3 \mathrm{~mL}$ aliquot of $2 \mathrm{M} \mathrm{HNO}_{3}$. A $0.2 \mathrm{~mL}$ aliquot of this solution was combined with a 6 $\mathrm{mL}$ aliquot of the lanthanide tracer solution which had been activated in the SRNL NAA facility. A $0.5 \mathrm{~mL}$ aliquot of the combined tracer solution was analyzed by GPHA for reference and the remainder of the solution was used in the extraction experiments.

\section{Extraction Experiments}

Actinide/lanthanide separations using the TALPEAK process are generally performed using an aqueous phase containing a 1.5 M lactic acid buffer and 0.05 M DTPA and an organic phase containing 1.0 M HDEHP in a hydrocarbon diluent [7]. To measure the distribution of the actinide and lanthanide elements between the aqueous and organic phases in the process, the alternate complexants were dissolved in $1.5 \mathrm{M}$ lactic acid. The $1.5 \mathrm{M}$ lactic acid solution was prepared by diluting $11.4 \mathrm{M}(85 \mathrm{wt} \%)$ lactic acid with deionized water. The concentrations of the complexants used in the extraction experiments are given in Table 3. A series of extractions was also performed using DTPA in the aqueous phase to validate the experimental methods which we developed. To dissolve the DTPA in $1.5 \mathrm{M}$ lactic acid, it was necessary to slowly add $7.8 \mathrm{M}(29 \mathrm{wt} \%) \mathrm{NH}_{4} \mathrm{OH}$ to raise the $\mathrm{pH}$ until all solids dissolved.

The extraction experiments were initially performed using a 1.0 M solution of HDEHP in dodecane as the organic phase. The solvent was prepared by diluting the desired mass of (97\%) HDEHP with ( $\geq 99 \%)$ dodecane. However, in the initial experiments the extent of extraction for a number of the lanthanide elements into the organic phase was nearly quantitative leaving insufficient activity in the aqueous phase for analysis. For this reason, we chose to reduce the HDEHP concentration to $0.125 \mathrm{M}$ to reduce the extent of extraction.

The control of the aqueous phase $\mathrm{pH}$ in the TALSPEAK process is crucial to achieving an efficient separation of the actinides from the lanthanides. The most efficient separations occur in a $\mathrm{pH}$ range between approximately 3.0 and 4.0 [7]. To evaluate the effect of $\mathrm{pH}$ on the efficacy of the alternate complexants in facilitating an actinide/lanthanide separation, we chose to perform extraction experiments at nominally $\mathrm{pH} 2,3$, and 4 . Each extraction was performed in triplicate. To prepare for each series of extractions, six 24-mL aliquots of each complexant in $1.5 \mathrm{M}$ lactic acid were prepared. Two solutions were adjusted to $\mathrm{pH} 2,3$, and 4 , respectively, by the drop-wise addition of $7.8 \mathrm{M} \mathrm{NH}_{4} \mathrm{OH}$. The $\mathrm{pH}$ of the solutions was measured using a calibrated $\mathrm{pH}$ meter. One set

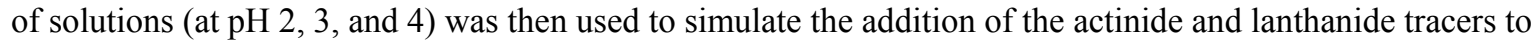
measure the volume of $3.9 \mathrm{M} \mathrm{NH}_{4} \mathrm{OH}$ required to readjust the $\mathrm{pH}$ to the designated values. The simulation was performed by combining the proper volume of the unirradiated lanthanide solution used to prepare the tracers with the proper volume and concentration of $\mathrm{HNO}_{3}$ to simulate the addition of the other tracers $\left({ }^{154} \mathrm{Eu},{ }^{239} \mathrm{~Np}\right.$, ${ }^{238} \mathrm{Pu}$, and

$\left.{ }^{241} \mathrm{Am}\right)$. Calibrated pipettes were used for all solution transfers including the addition of $3.9 \mathrm{M} \mathrm{NH}_{4} \mathrm{OH}$ after adding the simulated tracers to the complexant solutions.

To prepare the aqueous phase for each series of extractions, a $1.5 \mathrm{~mL}$ aliquot of the combined tracer solutions was added to each of the three remaining $(24 \mathrm{~mL})$ aliquots of complexant solution in a radiochemical hood. The bottles were capped and the solution was shaken for $10 \mathrm{~s}$ to mix the contents. The appropriate volume of $3.9 \mathrm{M} \mathrm{NH}_{4} \mathrm{OH}$ (previously measured) was added to each solution to readjust the $\mathrm{pH}$ to the designated values. An approximate $5 \mathrm{~mL}$ aliquot of each solution was transferred to a clean plastic vial to measure the actual $\mathrm{pH}$ of the solution. The $\mathrm{pH}$ electrode was rinsed in three, $5 \mathrm{~mL}$ aliquots of complexant solution (adjusted to the appropriate $\mathrm{pH}$ ) prior to measuring the $\mathrm{pH}$ of the tracer-containing solutions. A $6 \mathrm{~mL}$ aliquot of each solution was transferred to three, 30 $\mathrm{mL}$ vials followed by the addition of a $6 \mathrm{~mL}$ aliquot of the HDEHP solvent. A $6 \mathrm{~mL}: 6 \mathrm{~mL}$ organic to aqueous ratio 
was used in the majority of the extraction experiments. The vials were capped and agitated using a vortex mixer for $120 \mathrm{~s}$. The vials were placed in a thin plastic bag for secondary containment. The phases were then allowed to disengage and equilibrate for $600 \mathrm{~s}$. The organic phase was removed using a transfer pipette and a $5 \mathrm{~mL}$ sample prepared and analyzed by GPHA. To remove any residual solvent from the aqueous phase prior to sampling, we found that it was effective to add a $3 \mathrm{~mL}$ aliquot of dodecane to the vial and agitate for $20 \mathrm{~s}$ using a vortex mixer. After phase separation, the organic phase was discarded and a $5 \mathrm{~mL}$ sample of the aqueous phase was prepared and analyzed by GPHA. This procedures assumes that the lanthanide and actinide equilibrium concentrations in the aqueous phase were not significantly changed. All of the extraction experiments were performed at room temperature $\left(22 \pm 1{ }^{\circ} \mathrm{C}\right)$.

\section{Results}

The extraction of the lanthanides and actinides proceeds predominantly by a cation exchange/chelating mechanism. Under most conditions (for the trivalent elements), three hydrogen-bonded HDEHP dimmers $\left((\mathrm{HA})_{2}\right)$ surround one metal ion $\left(\mathrm{M}^{3+}\right)$ (equation 1) [7].

$$
\mathrm{M}_{(\mathrm{aq})}^{3+}+3(\mathrm{HA})_{2(\mathrm{or})} \rightleftarrows \mathrm{M}(\mathrm{AHA})_{3(\mathrm{or})}+3 \mathrm{H}_{(\mathrm{aq})}^{+}
$$

Based on this stoichiometry and the mass of the lanthanides used to prepare the tracer solution (Table 2), complete extraction of the metals would have resulted in approximately $70 \%$ loading of the $0.125 \mathrm{M}$ HDEHP solvent. In extraction experiments performed with $\mathrm{NH}_{4} \mathrm{SCN}$ and TPEN (see later discussion), solvent loading became an issue for the most favorable extraction conditions (i.e., $\mathrm{pH} 4$ ) due to third phase formation.

The activity of the actinide and lanthanide tracers measured in the aqueous and organic phases from the extractions were used to calculate distribution coefficients. The short half-life lanthanide activities were decay-corrected to the time of analysis. The distribution coefficient $\left(\mathrm{D}_{\mathrm{M}, \mathrm{o} / \mathrm{a}}\right)$ is defined as the ratio of the activity of the metal in the organic phase $\left(\mathrm{A}_{\mathrm{M}, \mathrm{o}}\right)$ to the activity of the metal in the aqueous phase $\left(\mathrm{A}_{\mathrm{M}, \mathrm{a}}\right)($ equation 2$)$.

$$
\mathrm{D}_{\mathrm{M}, \mathrm{o} / \mathrm{a}}=\frac{\mathrm{A}_{\mathrm{M}, \mathrm{o}}}{\mathrm{A}_{\mathrm{M}, \mathrm{a}}}
$$

To validate our experimental methods, a traditional TALSPEAK extraction was performed using $1.5 \mathrm{M}$ lactic acid and $0.05 \mathrm{M}$ DTPA in the aqueous phase. The distribution coefficients are plotted in Fig. 1 as a function of the inverse ionic radii (for a coordination number of eight). The error bars shown on the plot represent one standard deviation in the average distribution coefficient. The distribution data are consistent with the order of extractability of the lanthanides reported by Weaver and Kapplemann [9]. Although the distribution coefficients measured in this study are smaller due to the lower HDEHP concentration, the shape of curves through the data are generally the same. The minimum lanthanide distribution coefficient occurs at $\mathrm{Nd}(1 / \mathrm{r}=0.903)$ and the $\mathrm{Am}(1 / \mathrm{r}=0.904)$ distribution coefficient (at $\mathrm{pH} 3$ ) is greater than two orders of magnitude smaller than the lanthanide distribution coefficients. Both observations are consistent with the previous study. Fig. 1 also illustrates the effect of $\mathrm{pH}$ on the lanthanide and actinide distribution coefficients. The distribution coefficients increase with decreasing $\mathrm{pH}$ (over the range of investigation) which indicates the effect of a lesser degree of complexation of the metal ion in the aqueous phase with either lactate or DTPA. As the $\mathrm{pH}$ continues to drop, the distribution coefficients would be expected to drop due to the protonation of the HDEHP solvent which reduces the number of available complexation (i.e., ion exchange) sites [7].

To evaluate the potential for separating the actinides from the lanthanides using an alternate complexant in the TALSPEAK process, it is convenient to define the separation factor $\left(\mathrm{SF}_{\mathrm{An}}\right)$ as the ratio of the lanthanide to the actinide distribution coefficient (equation 3).

$$
\mathrm{SF}_{\mathrm{An}}=\frac{\mathrm{D}_{\mathrm{Ln}}}{\mathrm{D}_{\mathrm{An}}}
$$


A separation factor significantly greater than unity (e.g., $>10$ ) would be required to efficiently separate the actinides from the lanthanides using the TALSPEAK process. The separation factors calculated for the use of the alternate complexants varied with both the complexant and the size of the lanthanide ion. The hydroxamic acids were the least effective of the complexants which were tested in preventing the extraction of the actinide elements into the organic phase. The separation factors for the use of SHA in the TALSPEAK process were approximately unity for each of the actinide elements. The separation factors calculated when AHA or BHA were present in the aqueous phase were generally based on lower bounding lanthanide distribution coefficients. The experiments with these complexants were performed prior to reducing the HDEHP concentration in the solvent from 1 to $0.125 \mathrm{M}$ to reduce the extent of extraction; therefore, most of the lanthanide activity levels in the aqueous phase were based on detection limits which provided a lower bound for the distribution coefficient. Separation factors calculated in this manner do not reflect the true liquid-liquid equilibrium; however, some general observations concerning the use of AHA and BHA in the TALSPEAK process can be still be made.

The actinide separation factors for the use of BHA in the aqueous phase generally ranged between 0.1 and 10; although, separation factors for the heaviest lanthanides used in this study (i.e., Dy and Ho) ranged from a low of 20 (for $\mathrm{Am}$ ) to a high of 80 (for $\mathrm{Pu}$ ). Lower bounding separation factors for the use of AHA in the aqueous phase (at $\mathrm{pH} 4)$ are shown in Fig. 2 as a function of the inverse ionic radius for the lanthanide series. The figure shows that the separation factors for $\mathrm{Np}$ and $\mathrm{Pu}$ were much higher than for Am. The higher separation factors for the 4+ actinides are consistent with the higher stability constants reported by Taylor et al. for the $\mathrm{Np}(\mathrm{IV})$ and $\mathrm{Pu}(\mathrm{IV})$-AHA complexes compared to the Am(III)-AHA complex [20]. The more stable complexes are retained in the aqueous phase to a greater extent. In addition, the stability constants reported by Taylor et al. for the Am(III) and $\mathrm{Ln}(\mathrm{III})$ AHA complexes are about the same order of magnitude; therefore, the distribution between HDEHP and an aqueous phase containing AHA would be expected to be about the same and little separation would be possible which is consistent with our results.

The separation factors measured for the use of TPEN (Fig. 3) and $\mathrm{NH}_{4} \mathrm{SCN}$ (Fig. 4) in the aqueous phase of the TALSPEAK process showed a dependence on the atomic number (i.e., size) of the lanthanide elements. This behavior is due to an increase in the distribution coefficients across the lanthanide series. The stability of the HDEHP-metal complex (see equation 1) compared to the stability of the TPEN/ $\mathrm{NH}_{4} \mathrm{SCN}$ or lactic acid complexes increases as the size of the metal ion decreases which resulted in the increased extent of extraction. The same behavior has also been observed during the extraction of Am and selected lanthanides from a $1 \mathrm{M}$ lactic acid solution by $0.2 \mathrm{M}$ HDEHP in dissopropylbenzene (i.e., without the presence of a complexant). At $\mathrm{pH} 1.8$ the separation factor for Am increased from 1.2 for $\mathrm{La}$ to $27 \mathrm{for} \mathrm{Eu}$. The same trend was also observed at $\mathrm{pH} 3.0$ where the Am separation factor increased from 5.4 for $\mathrm{Ce}$ to $41 \mathrm{for} \mathrm{Eu}$ [9]. The use of dissopropylbenzene as the diluent in the previous work prevents a direct comparison with the separation factors measured in the presence of TPEN and $\mathrm{NH}_{4} \mathrm{SCN}$. The use of aliphatic diluents was reported to increase distribution ratios but lowered the separation factors of Eu from Am [9].

The distribution data obtained for TPEN and $\mathrm{NH}_{4} \mathrm{SCN}$ were very limited at $\mathrm{pH} 4$. When the HDEHP solvent concentration was reduced from 1 to $0.125 \mathrm{M}$, the use of a more dilute solvent improved the precision of the measurements; however, the higher solvent loading resulted in third phase formation. Third phase formation is typically observed at high metal or mineral acid loading of the organic phase under suitable conditions. When these conditions are present, the organic phase splits into two layers; the light layer contains most of the diluent and little extractant and metal, and the heavy or third phase contains a high concentration of extractant and metal and little diluent [21].

We were able to obtain a limited amount of data at $\mathrm{pH} 4$ when TPEN was present in the aqueous phase by increasing the organic to aqueous ratio from 1:1 to 2:1 (i.e., $12 \mathrm{~mL}: 6 \mathrm{~mL}$ ). The separation factors measured using these conditions were generally the highest measured for the three actinides using a complexant other than DTPA. The DTPA separation factors measured at $\mathrm{pH} 4$ are provided in Fig. 5 for comparison. The data at $\mathrm{pH} 4$ also show a change in the order of extraction. At pH 2 and 3, for the use of both TPEN and $\mathrm{NH}_{4} \mathrm{SCN}$ in the aqueous phase, the separation factors decreased in the order $\mathrm{Am}>\mathrm{Np}>\mathrm{Pu}$. However, at $\mathrm{pH} 4$, the order changed to $\mathrm{Np}>\mathrm{Pu}>\mathrm{Am}$. At $\mathrm{pH} 4$, the $\mathrm{Np}(\mathrm{IV})$ and $\mathrm{Pu}(\mathrm{IV})$-TPEN complexes must have increased stability compared to the Am(III)-TPEN complex which limits their extraction to a greater extent, Additional experimentation would be required to verify this hypothesis. 


\section{Conclusions}

A series of solvent extraction experiments was performed to measure the distribution of the lanthanide and actinide elements in the TALSPEAK process using alternate complexants in the aqueous phase to identify potential replacements for DTPA which are less sensitive to $\mathrm{pH}$ control. A rapid and accurate method was developed for measuring the distribution coefficients based on the preparation of lanthanide tracers in the SRNL NAA facility. Distribution data for the TALSPEAK process generated using this method were consistent with data from the original process development study. The separation factors for the use of the alternate complexants varied with both the complexants and the size of the lanthanide ion; however, no conditions were identified which resulted in separation factors which consistently approached those measured for the use of DTPA.

The hydroxamic acids were the least effective of the complexants tested in preventing the extraction of the actinide elements. Separation factors for the use of BHA in the aqueous phase were generally $<10$; although the values for the heaviest lanthanides tested (Dy and Ho) ranged from a low of 20 (for Am) to a high of 80 (for Pu). Limited data at $\mathrm{pH} 4$ for the use of AHA in the TALSPEAK process showed that the separation factors for $\mathrm{Np}$ and $\mathrm{Pu}$ were significantly higher than for Am. The higher separation factors for the 4+ actinides are consistent with higher stability constants reported for the $\mathrm{Np}$ (IV) and $\mathrm{Pu}$ (IV)-AHA complexes compared to the Am(III)-AHA complex. The more stable complexes are retained in the aqueous phase to a greater extent.

The separation factors for the use of TPEN and $\mathrm{NH}_{4} \mathrm{SCN}$ in the TALSPEAK process showed a dependence on the size of the lanthanide ion due to an increase in the distribution coefficient with decreasing ionic radius. This behavior is due to the stability of the HDEHP-metal complex (compared to the stability of the TPEN/NH $\mathrm{NCN}_{4} \mathrm{SCr}$ lactic acid complexes) which increases as the size of the metal ions decrease. This behavior is consistent with the extraction behavior of actinide and lanthanide elements from a buffered lactate solution into HDEHP without the presence of a complexant. The use of TPEN and $\mathrm{NH}_{4} \mathrm{SCN}$ was susceptible to third phase formation at high solvent loadings at $\mathrm{pH}$ 4. The separations factors measured for a limited number of the lanthanide elements for the use of TPEN at these conditions were generally the highest measured for the three actinides using a complexant other than DTPA.

\section{References}

1. Nuclear Energy Research and Development Roadmap - Report to Congress (2010) United States Department of Energy Office of Nuclear Energy, Washington, DC

2. G. R. Choppin, J. Liljenzin, and J. Rydberg (2001) Radiochemistry and Nuclear Chemistry. ButterworthHeinemann, Woburn, MA, p 593

3. L. R. Morss, N. M. Edelstein, and J. Fuger (eds) (2006) The Chemistry of the Actinide and Transactinide Elements. vol. 2, $3^{\text {rd }}$ edn. Springer, Dordrecht, The Netherlands pp 841-844

4. L. R. Morss et al. pp 704-705

5. M. L. Hyder, W. C. Perkins, M. C. Thompson, G. A. Burney, E. R. Russell, H. P. Holcomb, and L. F. Landon (1979) Processing of Irradiated Enriched Uranium Fuels at the Savannah River Plant. DP-1500 E. I. du Pont de Nemours \& Co., Aiken, SC

6. C. E. Stevenson, E. A. Mason, and A. T. Gresky (eds) (1970) Progress in Nuclear Energy, Series III, Process Chemistry. vol. 4, Pergamon Press, New York, NY pp 517-522

7. M. Nilsson and K. L. Nash (2007) Solvent Extr Ion Exc 25:665-701

8. B. Weaver and F. A. Kappelmann (1964) Talspeak, A new method of separating americium and curium from the lanthanides by extraction from an aqueous solution of an aminopolyacetic acid complex with a monoacetic organophosphate or phosphonate. ORNL-3559 Union Carbide Corporation, Oak Ridge, TN

9. B. Weaver and F. A. Kappelmann (1968) J Inorg Nucl Chem, 30:263-272

10. I. Svantesson, I. Hagström, G. Persson, and J. O. Liljenzin (1979) Radiochem Radioa Let, 37(4-5):251-222

11. G. Von Andergee, F. L'Eplatternier, and G. Schwarzenbach (1963) Helv Chim Acta 46:1400

12. A. Barocas, F. Baroncelli, G. B. Biondi, and G. Grossi (1965) J Inorg Nucl Chem 28:2961-2967

13. M. P. Jensen, L. R. Morss, and J. V. Beitz, D. D. Ensor (2000) J Alloy Compd, 303-304:137-141

14. F. L. Moore (1964) Anal Chem 36:2158-2162

15. K. L. Nash (1999) Separ Sci Technol, 34(6-7):911-929

16. D. P. DiPrete, C. C. DiPrete, and R. A. Sigg (2008) J Radioanal Nucl Ch 277(1):43-47 
17. E. P. Horwitz, M. L. Dietz, R. Chiarizia, H. Diamond, S. L. Maxwell III, and M. Nelson (1995) Anal Chim Acta 310:63-78

18. S. F. Marsh (1989) Solvent Extr Ion Exc 7(5):889-908

19. E. P. Horwitz, D. R. McAlister, A. H. Bond, and R. E. Barrans, Jr, (2005) Solvent Extr Ion Exc 23:319-344

20. R. J. Taylor, S. I. Sinkov, and G. R. Choppin (2008) Complexation of Lanthanides and Actinides by Acetohydroxamic Acid. Proceedings of the International Solvent Extraction Conference, Tucson, AZ, September 15-19, 2008, B. A. Moyer (ed) Canadian Institute of Mining, Metallurgy and Petroleum, Montréal, Québec, Canada, pp 527-532.

21. R. Chiarizia, M. P. Jensen, M. Borkowski, J. R. Ferraro, P. Thiyagarajan, and K. C. Littrell (2003) Solvent Extr Ion Exc 21:1-27 
Table 1 Typical composition of PWR fuel elements [2]

\begin{tabular}{cc}
\hline \hline Element/Group & $\begin{array}{c}\text { Composition } \\
(\%)\end{array}$ \\
\hline $\mathrm{U}$ & 95.6 \\
$\mathrm{Pu}$ & 0.9 \\
Minor Actinides & 0.1 \\
Fission Products & 3.4 \\
\hline
\end{tabular}


Table 2. Production of lanthanide tracer solution in the SRNL NAA facility

\begin{tabular}{cccccc}
\hline \hline Element & Mass $^{(1)}$ & $\begin{array}{c}\text { Target } \\
\text { Isotope }\end{array}$ & Reaction & $\begin{array}{c}\text { Activation } \\
\text { Products }\end{array}$ & Half-life \\
\hline $\mathrm{La}$ & 0.354 & ${ }^{139} \mathrm{La}$ & $(\mathrm{n}, \gamma)$ & ${ }^{140} \mathrm{La}$ & $1.6781 \mathrm{~d}$ \\
$\mathrm{Ce}$ & 1.615 & ${ }^{140} \mathrm{Ce}$ & $(\mathrm{n}, \gamma)$ & ${ }^{141} \mathrm{Ce}$ & $32.501 \mathrm{~d}$ \\
& & ${ }^{142} \mathrm{Ce}$ & $(\mathrm{n}, \gamma)$ & ${ }^{143} \mathrm{Ce}$ & $1.3766 \mathrm{~d}$ \\
$\mathrm{Pr}$ & 0.354 & ${ }^{141} \mathrm{Pr}$ & $(\mathrm{n}, \gamma)$ & ${ }^{142} \mathrm{Pr}$ & $19.12 \mathrm{~h}$ \\
$\mathrm{Nd}$ & 2.960 & ${ }^{146} \mathrm{Nd}$ & $(\mathrm{n}, \gamma)$ & ${ }^{147} \mathrm{Nd}$ & $10.98 \mathrm{~d}$ \\
$\mathrm{Pm}$ & & ${ }^{150} \mathrm{Nd}$ & $(\mathrm{n}, \gamma), \beta$ decay & ${ }^{151} \mathrm{Pm}$ & $1.183 \mathrm{~d}$ \\
$\mathrm{Sm}$ & 0.177 & ${ }^{152} \mathrm{Sm}$ & $(\mathrm{n}, \gamma)$ & ${ }^{153} \mathrm{Sm}$ & $1.9285 \mathrm{~d}$ \\
$\mathrm{Gd}$ & 0.354 & ${ }^{152} \mathrm{Gd}$ & $(\mathrm{n}, \gamma)$ & ${ }^{153} \mathrm{Gd}$ & $240.4 \mathrm{~d}$ \\
$\mathrm{~Tb}$ & 0.354 & ${ }^{159} \mathrm{~Tb}$ & $(\mathrm{n}, \gamma)$ & ${ }^{160} \mathrm{~Tb}$ & $72.3 \mathrm{~d}$ \\
$\mathrm{Dy}$ & 1.010 & ${ }^{156} \mathrm{Dy}$ & $(\mathrm{n}, \gamma)$ & ${ }^{157} \mathrm{Dy}$ & $8.14 \mathrm{~h}$ \\
$\mathrm{Ho}$ & 0.204 & ${ }^{165} \mathrm{Ho}$ & $(\mathrm{n}, \gamma)$ & ${ }^{166} \mathrm{Ho}$ & $1.1151 \mathrm{~d}$ \\
\hline
\end{tabular}

(1) Mass in $100 \mathrm{~mL}$ of solution. 
Table 3. Complexant concentrations

\begin{tabular}{cc}
\hline \hline Complexant & $\begin{array}{c}\text { Concentration } \\
(\mathrm{M})\end{array}$ \\
\hline AHA & $0.05 / 0.5$ \\
BHA & 0.5 \\
SHA & 0.05 \\
TPEN & $0.03 / 0.05$ \\
$\mathrm{NH}_{4} \mathrm{SCN}$ & $0.05 / 0.5$ \\
DTPA & 0.05 \\
\hline
\end{tabular}


Fig. 1 Distribution coefficients for lanthanide and actinide elements in the TALSPEAK process

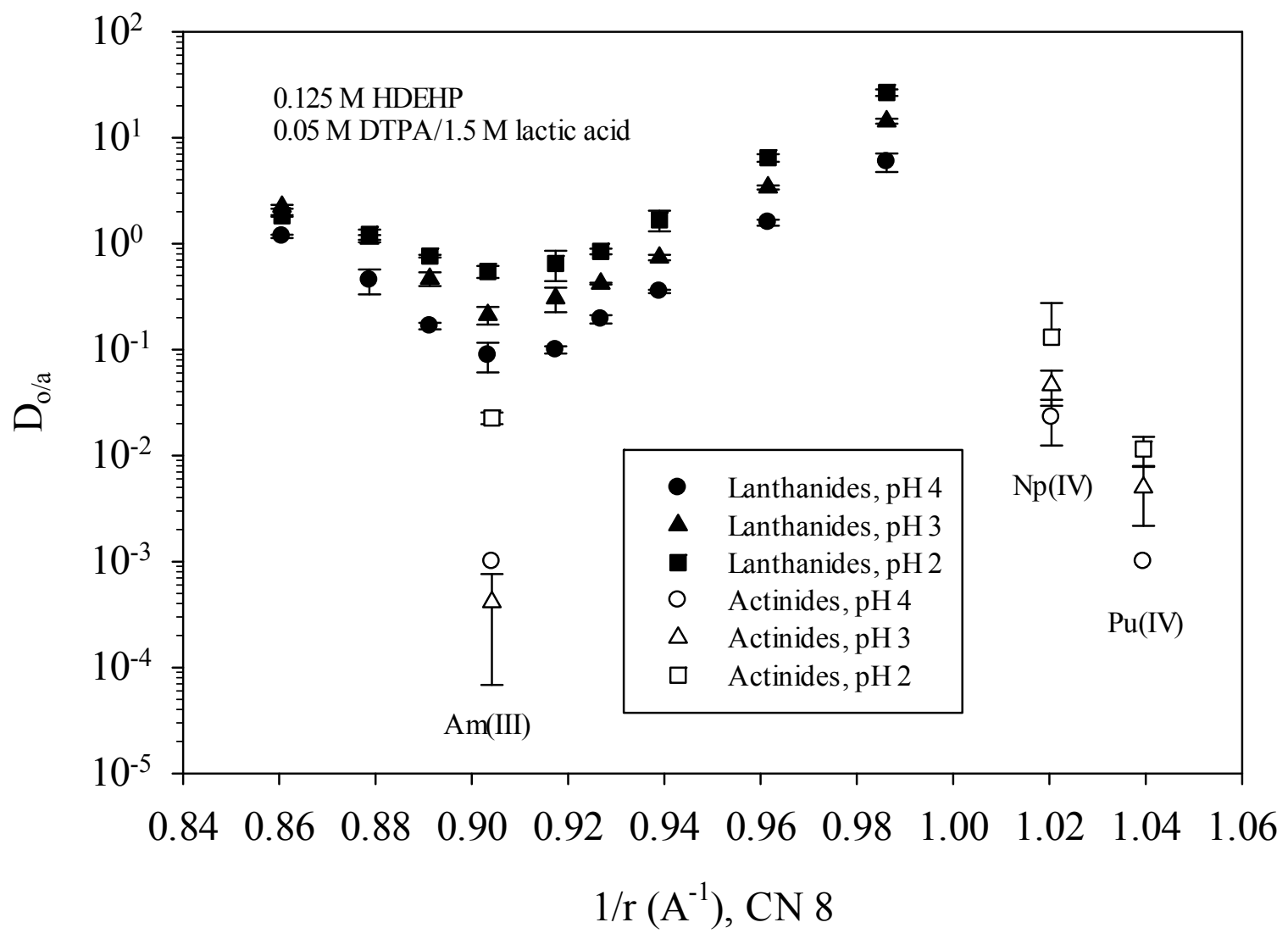


Fig. 2 Lower bounding actinide separation factors for the TALSPEAK process using AHA

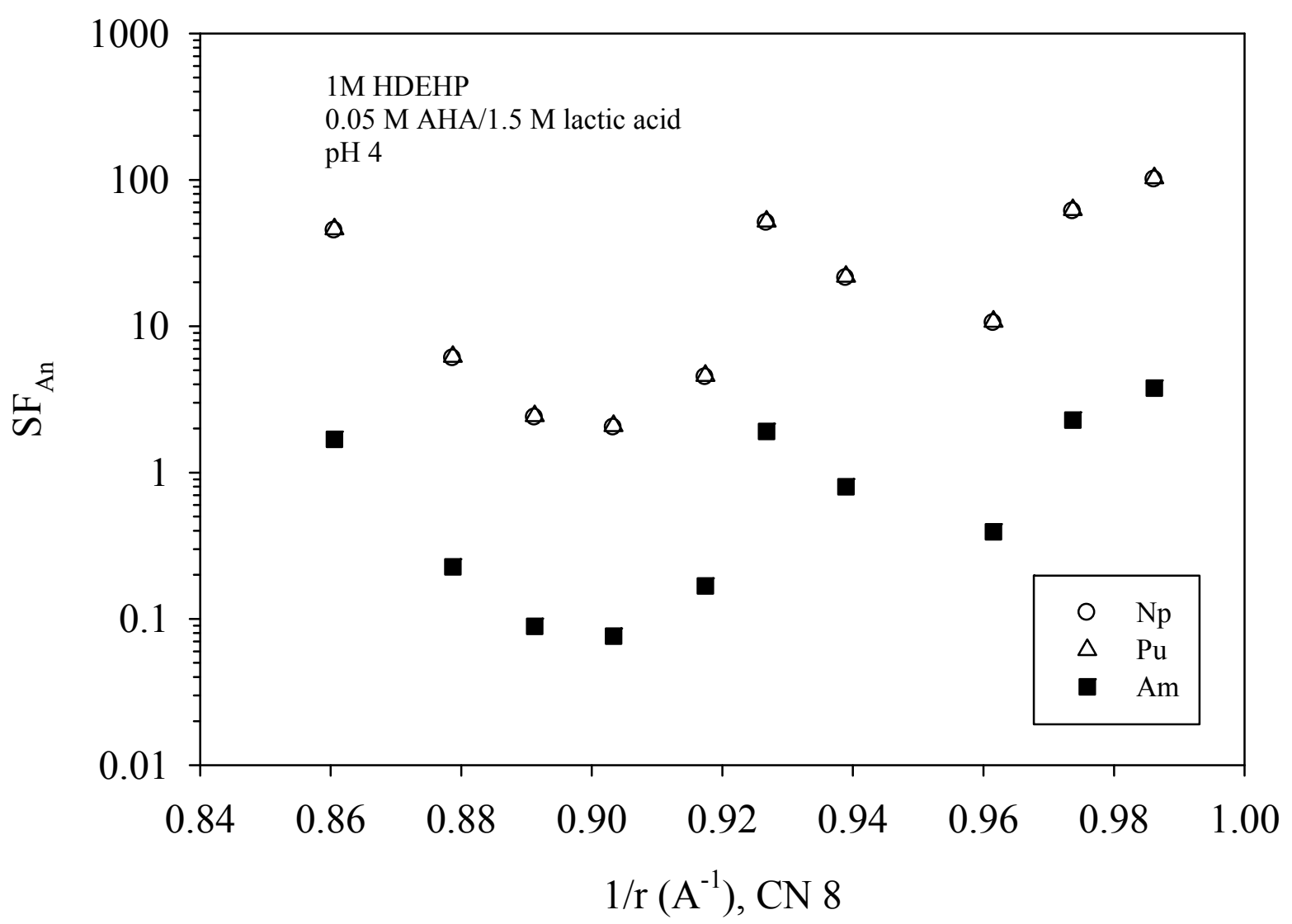


Fig. 3 Actinide separation factors for the TALSPEAK process using TPEN
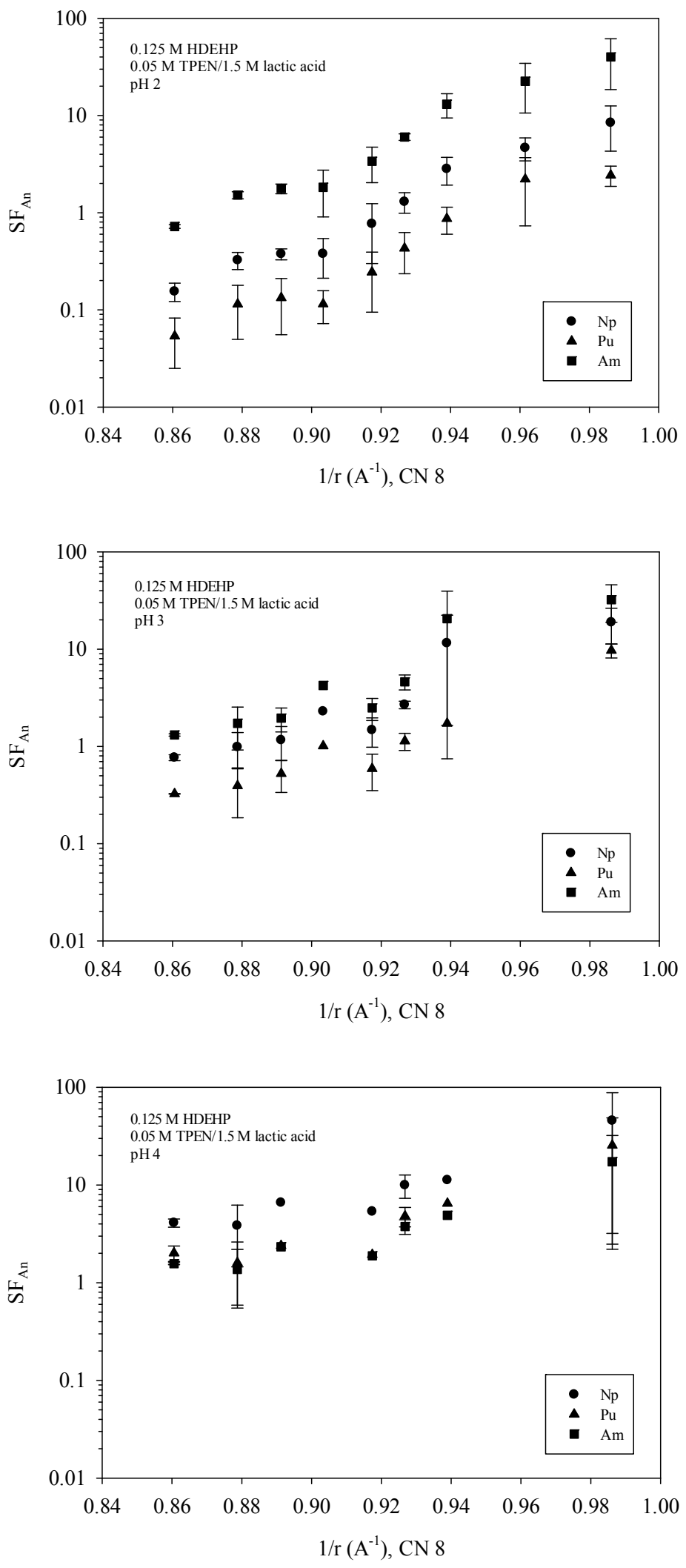
Fig. 4 Actinide separation factors for the TALSPEAK process using $\mathrm{NH}_{4} \mathrm{SCN}$
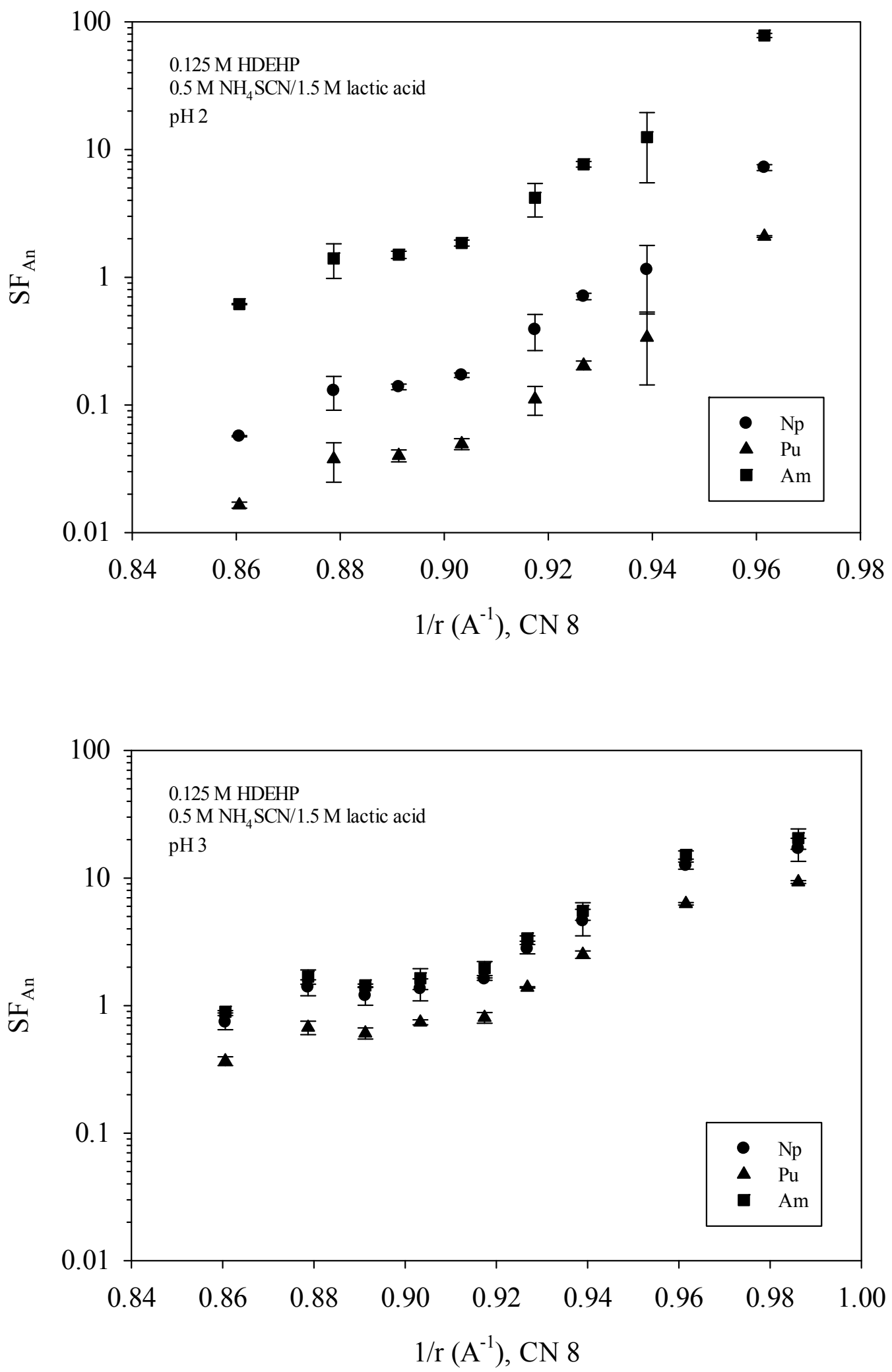
Fig. 5 Actinide separation factors for the TALSPEAK process using DTPA

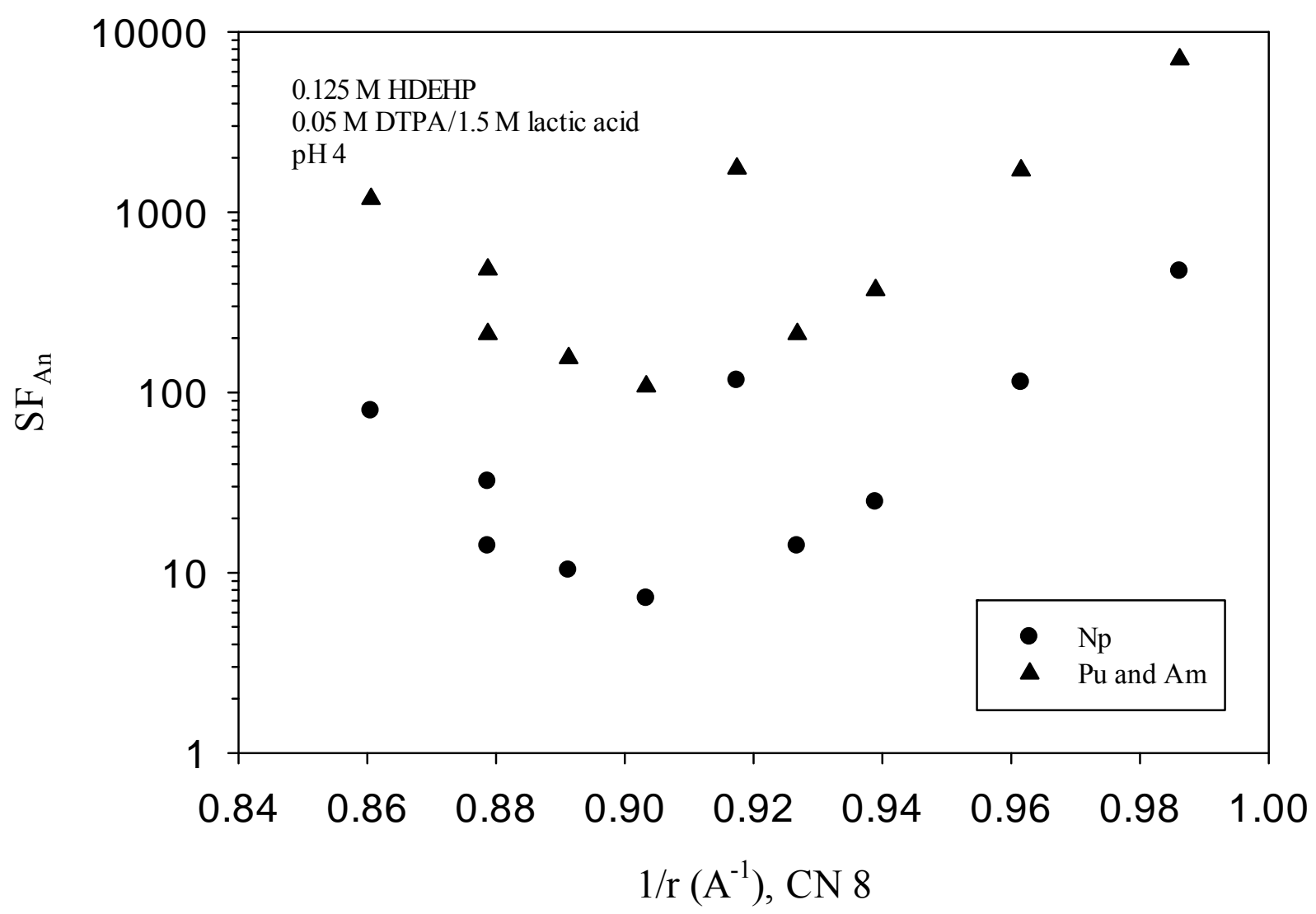

